\title{
CARACTERIZAÇÃO E DIVERSIDADE GENÉTICA DO CAPIM-ELEFANTE E SEUS HÍBRIDOS COM MILHETO MEDIANTE PADRÕES ISOENZIMÁTICOS ${ }^{1}$
}

\author{
NARA SUZY AGUIAR DE FREITAS², TÂNIA MARIA MUNIZ DE ARRUDA FALCÃO \\ HÉLIO ALMEIDA BURITY4 ${ }^{4}$, JOSÉ NILDO TABOSA ${ }^{5}$ e MÁRCIA VÂNUSA DA SILVA ${ }^{6}$
}

\begin{abstract}
RESUMO - Foram avaliadas isoenzimaticamente sete cultivares de capim-elefante (Pennisetum purpureum) e seus híbridos com milheto (P. americanum), selecionados pela Empresa Pernambucana de Pesquisa Agropecuária (IPA), visando à identificação de acessos. Foram estudados, em gel de poliacrilamida, os sistemas peroxidase (POX), esterase (EST), glutamato oxalacetato transaminase (GOT), leucina aminopeptidase (LAP), álcool-desidrogenase (ADH) e fosfatase ácida (ACP), em folhas jovens, aos 28 dias após o corte de uniformização. Não foi observada atividade isoenzimática da $\mathrm{ADH}$ e observou-se baixa resolução do sistema LAP, os quais não são indicados para caracterização dos germoplasmas. Os padrões de ACP, GOT, POX e EST permitiram conhecer os fenótipos dos 14 acessos estudados. Foram revelados 9, 3,13 e 19 diferentes padrões de bandas, respectivamente, sendo possível a identificação da coleção de forma rápida e segura utilizando apenas os padrões de esterase.

Termos para indexação: Pennisetum purpureum, Pennisetum americanum, gramíneas, isoenzimas, variação genética.
\end{abstract}

\section{CHARACTERIZATION AND GENETIC DIVERSITY OF ELEPHANT GRASS CULTIVARS AND THEIR HYBRIDS WITH MILLET THROUGH ISOENZYMATIC PATTERNS}

\begin{abstract}
The isoenzymatic patterns of seven cultivars of elephant grass (Pennisetum purpureum) and their seven hybrids with Pearl millet (P. americanum), selected by Empresa Pernambucana de Pesquisa Agropecuária (IPA), were evaluated to identify the accesses. In polyacrylamide gels, the systems peroxidase (POX), esterase (EST), glutamate oxaloacetate transaminase (GOT), leucine amino peptidase (LAP), alcohol dehydrogenase (ADH), and acid phosphatase (ACP), were studied in young leaves at 28 days after uniformization cut. It wasn't observed isoenzymatic activity of ADH and the efficiency of the LAP system was considered low, which suggest that both can not be indicated for germoplasm characterization. The patterns ACP, GOT, POX and EST allowed the identification of the 14 accesses studied, which revealed 9, 3, 13 and 19 different electrophoretic patterns respectively. Using the esterase system alone, it is possible to identify the germoplasm bank of elephant grass quickly and accurately

Index terms: Pennisetum purpureum, Pennisetum americanum, gramineae, isoenzymes, genetic variation.
\end{abstract}

\footnotetext{
${ }^{1}$ Aceito para publicação em 25 de janeiro de 2000 .

2 Biól., M.Sc., Universidade Federal Rural de Pernambuco (UFRPE)/Empresa Pernambucana de Pesquisa Agropecuária (IPA), Rua D. Manuel de Medeiros, s/n, Dois Irmãos, CEP 52171-900 Recife, PE. E-mail: narafreitas@zaz.com.br ${ }^{3}$ Biól., Dra., UFRPE.

${ }^{4}$ Eng. Agrôn., Ph.D., Embrapa/IPA, Av. Gen. San Martin, 1371, Bongi, CEP 50761-000 Recife, PE. E-mail burity@ipa.br

${ }^{5}$ Eng. Agrôn., M.Sc., IPA

${ }^{6}$ Eng. Agrôn., Estudante de Pós-graduação, Dep. de Biologia, Universidade Federal de Lavras (UFLA), Caixa Postal 37 , CEP 37200-000 Lavras, MG
}

\section{INTRODUÇÃO}

O capim-elefante tem se destacado por sua alta produtividade, o que faz dele uma das mais importantes forrageiras do mundo (Gupta, 1975; Santana et al., 1989; Schank, 1994). Além disso, o capim-elefante congrega diferentes tipos de materiais genéticos, como híbridos interespecíficos, ecotipos, clones e variedades que ampliam consideravelmente sua área de adaptação ambiental (Gonzalez \& Menezes, 1979). 
Um dos maiores problemas relacionados com a caracterização dos materiais que compõem os bancos de germoplasma de capim-elefante é a identificação segura dos acessos. Segundo Pereira (1994), uma das prioridades é a eliminação das duplicatas nos bancos de germoplasma, obtendo-se assim aumento da eficiência e redução no custo de manutenção das coleções. A existência de um grande número de acessos (sem controle genealógico), originário de um único programa de melhoramento, gera dúvidas sobre a diversidade genética do germoplasma e a representatividade de diferentes ecossistemas.

A descrição fenotípica dos acessos de capim-elefante tem sido realizada pela utilização de um conjunto de descritores, estabelecidos com base no conhecimento da variação do germoplasma. Os descritores mais comuns referem-se a caracteres morfológicos (altura da planta, número, comprimento e diâmetro dos internódios, comprimento e largura das folhas, presença de pêlos); caracteres reprodutivos (época de florescimento, comprimento, diâmetro e cor da inflorescência, tamanho da cariopse); caracteres agronômicos (relação folha/caule e produção de matéria seca) e caracteres bioquímicos (digestibilidade e valor bromatológico). No entanto, existem poucas informações sobre a estabilidade de expressão e capacidade discriminatória da maioria desses caracteres (Pereira, 1994), não havendo um número exato de descritores que permita distinguir, inequivocamente, as cultivares de capimelefante (Daher, 1993).

Tcacenco \& Botrel (1990) advertiram que os dados ou os fenótipos a serem utilizados na caracterização de cultivares devem apresentar variações intercultivares suficientemente significativas e constantes, salientando que os atributos escolhidos devem ter validade universal, isto é, não deve haver interação entre os mesmos e o ambiente onde eles estão sendo avaliados. Caso contrário, a validade da classificação gerada será restrita ao local e à época em que a avaliação foi efetuada.

A utilização de isoenzimas como marcadores moleculares e genéticos vem sendo empregada com grande sucesso, em diversos trabalhos nos quais se estuda a diversidade de germoplasma ou mesmo de populações naturais, o que também vem sendo estudado por meio de marcadores de DNA.
Relatos sobre a utilização da análise eletroforética na identificação de capim-elefante são raros. Entre os disponíveis, estão os trabalhos de Daher (1993), mostrando que eram repetições 25 acessos do total de 60 estudados, e o de Augustin \& Tcacenco (1993), que separaram 58 introduções em 23 grupos e salientaram que, em alguns casos, através da eletroforese foram reveladas variações intracultivares entre as amostras obtidas de diferentes localidades, evidenciando uma provável mistura varietal. Por sua vez, o milheto tem sido mais estudado que o capim-elefante via padrões eletroforéticos, tanto em termos de isoenzimas (Ozias-Akins et al., 1986) como de DNA (Tabaeizadeh et al., 1986; Jones et al., 1995; Sastrv et al., 1995).

Os estudos eletroforéticos de isoenzimas têm revelado um importante número de marcadores genéticos (Medina Filho, 1983; Alfenas et al., 1991; Ballve et al., 1991, 1995), os quais são mais precisos na distinção de cultivares do que as características morfológicas (Quirós, 1991). Embora em número limitado, vários locos isoenzimáticos podem ser analisados rápida e simultaneamente. Mesmo com técnicas moleculares mais modernas, as isoenzimas continuam sendo excelentes marcadores na análise genética que não requeira uma amostragem ampla do genoma (Ferreira \& Grattapaglia, 1995). Ademais, a análise de isoenzimas é um procedimento menos sujeito a variações ambientais (Alfenas et al., 1991; Quirós, 1991) quando comparada com os marcadores morfológicos, o que a torna mais eficaz. Pelo fato de a seqüência de aminoácidos que forma as proteínas ser determinada pela seqüência de nucleotídeos dos genes estruturais, o fenótipo eletroforético de proteínas e enzimas pode ser considerado como a expressão do produto primário do gene (Gottlieb, 1977). Além de ser relativamente simples, rápida e de alto valor informativo, permite individualizar organismos com elevado grau de parentesco (Alfenas et al., 1991), por serem as diferenças bioquímicas mais numerosas do que as morfológicas (Larsen, 1969). E, caso não se individualize todos os acessos, como no trabalho de Paula (1993) e Freitas et al. (1995), torna possível diminuir o número de grupos de acessos, formados apenas com os descritores morfológicos, como no trabalho de Daher (1993). 
Diversos marcadores isoenzimáticos já foram utilizados na identificação de gramíneas e outras plantas forrageiras (Almgard \& Clapham, 1975; Bassiri, 1976; Paula, 1993; Falcão \& Fernandes, 1994; Falcão \& Paula, 1994; Pinto et al., 1995), constituindo-se num valioso instrumento para os programas de melhoramento. Na Europa e nos Estados Unidos, os órgãos responsáveis pelo registro de novas linhagens e cultivares incluíram oficialmente os padrões eletroforéticos de proteínas em seus critérios de avaliação (Tanksley \& Orton, 1983).

No presente trabalho, estudaram-se cultivares e híbridos de capim-elefante através de sistemas isoenzimáticos, visando subsidiar uma identificação segura da coleção de capim-elefante mantida pela Empresa Pernambucana de Pesquisa Agropecuária para a região semi-árida do Estado de Pernambuco e verificar a diversidade genética da coleção a partir dos padrões isoenzimáticos obtidos.

\section{MATERIAL E MÉTODOS}

As cultivares utilizadas foram procedentes do Banco Ativo de Germoplasma (BAG) de capim-elefante da Estação Experimental de Vitória de Santo Antão - Empresa Pernambucana de Pesquisa Agropecuária (IPA). A relação das sete cultivares de capim-elefante e de sete híbridos com milheto, selecionados para o semi-árido de Pernambuco, origem e referência, estão mencionados na Tabela 1. Os materiais híbridos do BAG de Vitória de Santo Antão foram gerados a partir de blocos de cruzamentos entre a linha macho estéril de milheto $23 \mathrm{~A}$ e a cultivar Elefante B

Antes do plantio, 12 estacas de diferentes plantas de cada acesso foram colocadas para brotar em bandeja contendo areia lavada. Após 12 dias, três plantas de cada acesso foram transplantadas para vasos com capacidade de $20 \mathrm{~kg}$ de solo. Vinte e oito dias após o transplante, foi feito corte de uniformização, a $5 \mathrm{~cm}$ do solo. A irrigação e os tratos fitossanitários foram realizados quando necessários. Decorridos 28 dias do corte de uniformização foi realizada a coleta do material para análises isoenzimáticas O delineamento foi o inteiramente casualizado, com $14 \times 3$ repetições de tratamentos.

Os sistemas isoenzimáticos utilizados foram álcooldesidrogenase, leucina aminopeptidase, fosfatase ácida, glutamato oxaloacetato transaminase, peroxidase e esterase Para a migração eletroforética foram utilizados os sistemas de tampões descontínuos de Poulik (1957) e de Scandalios (1969) (Tabela 2)

As amostras foram obtidas a partir da maceração individual, em almofariz, de $2 \mathrm{~g}$ de um estoque de folhas mais novas, coletadas aos 28 dias após o corte de uniformização, para as três repetições de cada tratamento. Como solução extratora foi utilizado $1,5 \mathrm{~mL}$ de tampão $\mathrm{A}+\mathrm{B}$ (Tabela 2). Os homogeneizados de cada amostra foram centrifugados a $40.000 \mathrm{rpm}$ durante 20 minutos, a $8^{\circ} \mathrm{C}$. Em seguida, os sobrenadantes foram armazenados a $-10^{\circ} \mathrm{C}$ até a aplicação das amostras nos géis, o que no máximo durava 72 horas. As amostras foram marcadas com azul de Bromofenol ( $1 \% \mathrm{p} / \mathrm{v}$ em álcool etílico).

A migração eletroforética foi conduzida a um potencial de $9,0 \mathrm{~V} / \mathrm{cm}$, até $9 \mathrm{~cm}$ de migração para o ânodo. Após a corrida eletroforética, efetuou-se a revelação específica das proteínas para cada sistema enzimático. A revelação dos sistemas isoenzimáticos foi baseada nos protocolos de revelação de Scandalios (1969) para EST e LAP, Shaw \& Prasad (1970) para ACP e ADH e Alfenas et al. (1991) para POX e GOT. Os padrões de bandas dos zimogramas foram elaborados a partir da metodologia utilizada por Kumar et al. (1995), que usaram uma escala arbitrária para numerar as bandas reveladas nos géis

As bandas instáveis (pouco definidas ou difusas) foram desconsideradas, estudando-se apenas as bandas consistentes (bem definidas ou que apareceram em todos os géis). Com objetivo de evitar eventuais erros de leitura, a aplicação das amostras nos géis foi aleatória quanto à ordem da aplicação, em cada uma das três repetições.

Os dados de similaridade genética foram expressos em frações, considerando as análises dos sistemas que mostraram atividade isoenzimática, segundo o Índice de Jaccard, utilizado por Nair et al. (1971)

\section{RESULTADOS E DISCUSSÃO}

\section{Avaliação isoenzimática}

Em uma etapa prévia à analise, foram realizados testes preliminares de ajuste das metodologias. Essa etapa teve como objetivo determinar os tecidos e estádios de desenvolvimento mais adequados para a observação da atividade enzimática, bem como o grau de variabilidade genética para cada sistema utilizado. Nos testes preliminares foram também analisados tecidos do meristema apical aéreo e de pontas de raízes.

Embora, nos testes preliminares, tenha sido observado um considerável número de bandas em teci- 
do de meristema apical aéreo e ponta de raiz, o maior número de bandas foi obtido em tecido de folhas jovens. Enquanto Daher (1993) observou maior número de padrões eletroforéticos em meristema apical de capim-elefante, após estudar os mesmos tecidos, Augustin \& Tcacenco (1993) relataram um elevado polimorfismo entre cultivares de capim-elefante, utilizando folhas jovens. A divergência entre os resultados deve estar relacionada com diferenças bioquímicas ocorrentes em estádios específicos de desenvolvimento (Larsen, 1969).

Diferença na atividade isoenzimática, associada a estádios diferentes de crescimento, é uma das limitações do uso das isoenzimas como marcadores moleculares (Ferreira \& Grattapaglia, 1995). Todavia, embora seja de máxima importância o controle rigoroso da idade de coleta do material, análises de um único tecido em diferentes estádios do desenvolvimento podem ser de alta valia, visto que podem ser observadas variações nos perfis, importantes em análises comparativas de materiais geneticamente próximos (Falcão \& Paula, 1994). Essas variações podem ser refletidas no aparecimento de diferentes bandas no gel ou na variação da intensidade de suas atividades. Diferenças nos padrões isoenzimáticos podem também estar relacionadas com o pH e composição da solução tampão, voltagem, amperagem, meio suporte (Ballve et al., 1991, 1995).

TABELA 1. Origem e referência das sete cultivares de capim-elefante e de sete híbridos com milheto, selecionados para o semi-árido de Pernambuco.

\begin{tabular}{llc}
\hline Cultivares e híbridos & \multicolumn{1}{c}{ Origem } & Número de referência (IPA) \\
\hline Mole de Volta Grande & Coronel Pacheco, $\mathrm{MG}^{2}$ & $475-79$ \\
Australiano & Coronel Pacheco, $\mathrm{MG}^{2}$ & $903-77$ \\
5054A x Elefante B & Coronel Pacheco, $\mathrm{MG}^{2}$ & $\mathrm{HV}-204$ \\
23A x Elefante B & Vitória de Santo Antão, PE & $\mathrm{HV}-241$ \\
23A x Elefante B & Vitória de Santo Antão, PE & $\mathrm{HV}-268$ \\
23A x Elefante B & Vitória de Santo Antão, PE & HV-281 \\
23A x Elefante B & Vitória de Santo Antão, PE & HV-290 \\
23A x Elefante B & Vitória de Santo Antão, PE & HV-400 \\
23A x Elefante B & Vitória de Santo Antão, PE & HV-296 \\
Cameroon & Coronel Pacheco, $\mathrm{MG}^{3}$ & $\mathrm{IBI}$ \\
Gramafante & Coronel Pacheco, $\mathrm{MG}^{2}$ & - \\
Venezuela & Coronel Pacheco, $\mathrm{MG}^{2}$ & - \\
Elefante Roxo & Coronel Pacheco, $\mathrm{MG}^{2}$ & - \\
Elefante B & Coronel Pacheco, $\mathrm{MG}^{2}$ & - \\
\hline
\end{tabular}

1 Empresa Pernambucana de Pesquisa Agropecuária ( IPA)

2 Embrapa-Centro Nacional de Pesquisa em Gado de Leite

3 IPA-E.E. de Vitória de Santo Antão, PE.

TABELA 2. Soluções-tampão utilizadas nas cubas-eletrodos e géis.

\begin{tabular}{|c|c|c|}
\hline Sistemas isoenzimáticos & Tampões e concentrações dos géis & Tampões das cubas-eletrodos \\
\hline $\begin{array}{l}\text { Esterase, leucina aminopeptidase } \\
\text { (LAP), fosfatase ácida e álcool } \\
\text { desidrogenase }\end{array}$ & $\begin{array}{l}A+B(1: 9) \text { a } 7 \%(A=\text { borato de lítio } \\
\left.B=\text { Tris } \text { Citrato }^{2}\right)\end{array}$ & Borato de lítio \\
\hline $\begin{array}{l}\text { Glutamato oxalacetato } \\
\text { transaminase (GOT) e Peroxidase } \\
(\mathrm{POX})\end{array}$ & $\begin{array}{l}\text { Tris } 6,2 \mathrm{~g} \text {; ácido cítrico } 0,96 \mathrm{~g} \text {; água } \\
\text { destilada para completar } 1 \mathrm{~L}, \mathrm{pH}=8,6 \text {. } \\
\text { GOT }(9 \%) \text { e POX }(6 \%)\end{array}$ & $\begin{array}{l}\text { Ácido bórico } 18,54 \mathrm{~g} \text {; } \mathrm{NaOH} 2 \mathrm{~g} \text {; } \\
\text { água destilada para completar } 1 \mathrm{~L} \text {, } \\
\mathrm{pH}=8,0\end{array}$ \\
\hline
\end{tabular}

${ }^{1}$ Hidróxido de lítio anidro $1,2 \mathrm{~g}$; ácido bórico (anidro) $11,89 \mathrm{~g}$; água destilada para completar $1 \mathrm{~L}, \mathrm{pH}=8,3$

2 Tris 6,2 g; ácido cítrico anidrol,6 g; água destilada para completar $1 \mathrm{~L}, \mathrm{pH}=8,3$. 
Não foi observada atividade isoenzimática da álcool-desidrogenase $(\mathrm{ADH})$ nas cultivares estudadas. Todavia, Ozias-Akins et al. (1986) observaram atividade ao estudarem híbridos de Pennisetum americanum (milheto) x Panicum maximum Jacq. (capim-colonião ou capim-guiné), aos 14 dias após o cultivo in vitro. Algumas hipóteses podem justificar esses resultados divergentes, tais como: interação e a contribuição diferencial do patrimônio genético de $P$. maximum, no híbrido analisado pelos autores; variações resultantes do próprio processo do cultivo in vitro; a não correspondência entre 14 dias de cultivo in vitro e 28 dias após o corte de uniformização. Não foi observada boa resolução para o sistema isoenzimático leucina aminopeptidase (LAP), concordando com os resultados de Daher (1993), que também não o utilizou após os testes preliminares.

Os zimogramas dos sistemas fosfatase ácida (ACP), glutamato oxaloacetato transaminase (GOT), peroxidase (POX) e esterase (EST) revelaram uma elevada variabilidade quanto ao número de bandas e às diferentes intensidades de coloração, as quais podem refletir atividade diferencial.

Para o sistema ACP, a cultivar que apresentou maior número de bandas foi a Gramafante, com oito, seguida pelo híbrido HV-204, com seis. Os materiais que apresentaram o menor número de bandas foram os híbridos HV-241 e HV-296 e a cultivar Cameroon, com três bandas (Fig. 1). A banda ACP-5 foi revelada em todas as cultivares estudadas, diferindo apenas na intensidade de coloração. Entre as cultivares Mole de Volta Grande, Elefante Roxo e o híbrido HV-400, não houve diferenças nos padrões de bandas e na intensidade de coloração. Por sua vez, a cultivar Cameroon e o híbrido HV-296, que apresentaram o mesmo padrão eletroforético para ACP, diferenciaram-se na intensidade de coloração das bandas ACP-5, ACP-6 e ACP-7, tendo estas sido reveladas mais intensamente no híbrido HV-296. Todos os demais materiais apresentaram diferentes padrões de bandas para ACP. Daher (1993) não obteve resultados significativos para o sistema ACP, para o qual este autor não foi além de ensaios preliminares. Já Augustin \& Tcacenco (1993) encontraram 13 bandas polimórficas.

Em relação ao sistema isoenzimático da GOT, neste trabalho foi possível a visualização de apenas três bandas, das quais uma foi revelada fortemente em todos os materiais. Daher (1993), ao contrário, observou oito diferentes bandas para o mesmo sistema entre os 60 acessos de capim-elefante que estudou. O híbrido HV-204 e as cultivares Cameroon, Venezuela e Elefante B mostraram duas bandas, as demais mostraram apenas uma. O híbrido HV-204 e a cultivar Elefante B apresentaram as bandas GOT-1 e GOT-3, e as cultivares Cameroon e Venezuela apresentaram as bandas GOT-2 e GOT-3 (Fig. 2).

No que diz respeito ao sistema POX, foi possível verificar uma grande diversidade de padrões de bandas anódicas e catódicas (Fig. 3), inclusive entre acessos Mole de Volta Grande, Roxo, Elefante B, Cameroon e Gramafante, os quais, quando analisados por Daher (1993), apresentaram um único padrão eletroforético. A banda POX-8 foi revelada em todos os materiais analisados. Por sua vez, apenas a cultivar Elefante Roxo não apresentou a banda POX-3, porém foi a única que apresentou a banda POX-2. É importante salientar que a cultivar Elefante Roxo é morfologicamente distinta das demais estudadas, diferenciando-se pela coloração das lâminas foliares.

Bandas $\alpha$-esterase foram detectadas em todas as 13 regiões esterásicas reveladas enquanto bandas

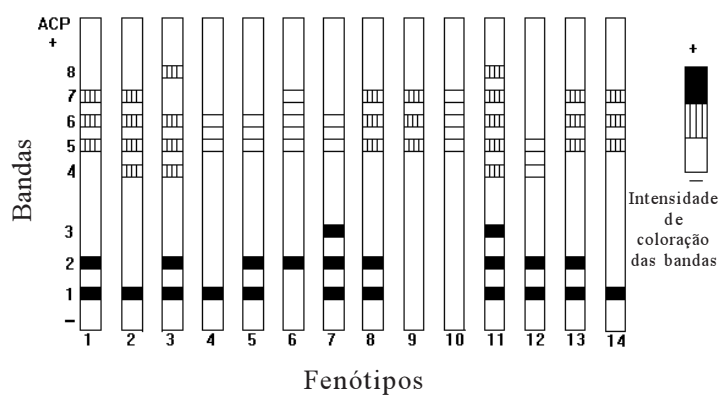

FIG. 1. Zimograma de fosfatase ácida (ACP) de tecido foliar, aos 28 dias após o corte de uniformização, dos 14 genótipos de capim-elefante, selecionados para o semi-árido de Pernambuco. Designações dos genótipos: 1: Mole de Volta Grande; 2: Australiano; 3: HV-204; 4: HV-241; 5: HV-268; 6: HV-281; 7: HV-290; 8: HV-400; 9: HV-296; 10: Cameroon; 11: Gramafante; 12: Venezuela; 13: Elefante Roxo; 14: Elefante B.

Pesq. agropec. bras., Brasília, v.35, n.6, p.1125-1133, jun. 2000 
$\beta$-esterase foram detectadas em apenas seis, do total de 13 regiões, conforme mostrado na Fig. 4. Portanto, para os diferentes materiais, foram reveladas $\alpha$ - e $\beta$-esterase em uma mesma região. Augustin \& Tcacenco (1993) obtiveram $9 \alpha$ - e 6 de $\beta$-esterases, em que três regiões foram comuns a $\alpha$-e $\beta$-esterases nos diferentes materiais analisados, perfazendo um total de 15 bandas esterásicas. Se seguida a mesma metodologia dos referidos autores, poder-se-á considerar 19 regiões esterásicas, uma vez que foram reveladas $13 \alpha$-esterases e seis $\beta$-esterases. Por sua vez, Daher (1993) encontrou 12 diferentes regiões de bandas para este sistema isoenzimático e não relatou o número e a presença de bandas $\alpha$ - e $\beta$-esterase, mesmo usando os mesmos substratos na coloração desse sistema protéico, a saber, $\alpha$ - e $\beta$-naftilacetato. Resultados semelhantes, ou seja, nos quais o sistema esterásico foi muito importante para a identificação de diferentes materiais genéticos de uma mesma espécie, foram obtidos por Paula (1993), que individualizou todos os acessos estudados de batata-doce através desse sistema protéico, e por Falcão \& Fernandes (1994), Falcão \& Paula (1994) e Pinto et al. (1995) para cultivares de trigo, batata-doce e soja, respectivamente. $\mathrm{O}$ que mostra a importância das esterases nessa modalidade de trabalho.

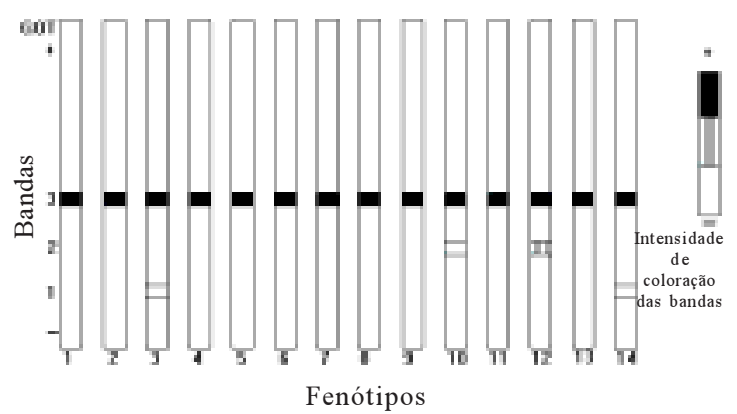

FIG. 2. Zimograma de glutamato oxalacetato transaminase (GOT) de tecido foliar, aos 28 dias após o corte de uniformização, dos 14 genótipos de capim-elefante, selecionados para o semi-árido de Pernambuco. Designações dos genótipos: 1: Mole de Volta Grande; 2: Australiano; 3: HV-204; 4: HV-241; 5: HV-268; 6: HV-281; 7: HV-290; 8: HV-400; 9: HV-296; 10: Cameroon; 11: Gramafante; 12: Venezuela; 13: Elefante Roxo; 14: Elefante B.
Analisando-se o zimograma do sistema EST, verifica-se que as sete regiões mais anódicas apresentaram apenas bandas $\alpha$-esterase. Entre todas as bandas reveladas para o sistema EST, a única que foi detectada em todos os materiais analisados foi a EST-6, sendo bandas $\alpha$ - e $\beta$-esterase para 11 e três materiais respectivamente. As bandas EST-8, EST-7 e EST-11 foram reveladas em apenas uma das cultivares analisadas, a saber, EST-8 em Mole de Volta Grande, EST-7 em Elefante B e EST-11 no híbrido HV-268.

A importância do sistema EST em relação ao POX pode ser ressaltada pela sua capacidade discriminatória das cultivares Gramafante e Venezuela. Pelo sistema POX, essas cultivares mostraram as mesmas bandas, enquanto pelo sistema EST foram reveladas as bandas EST-2, EST-10 e EST-13, exclusivamente para a cultivar Gramafante, e EST-12 exclusivamente para a cultivar Venezuela (Fig. 4). Todavia, embora a diferenciação dessas cultivares não tenha sido conseguida através dos padrões de POX, é possível sua distinção pela intensidade de coloração das bandas POX-3 e POX-8, as quais se apresentaram mais fortemente coradas na cultivar Gramafante que na cultivar Venezuela (Fig. 3).

Almgard \& Clapham (1975) selecionaram EST, ACP, POX e GOT, entre 18 sistemas isoenzimáticos,

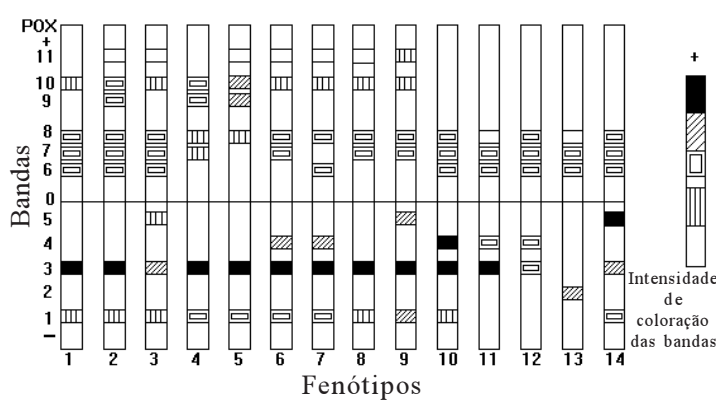

FIG. 3. Zimograma de peroxidase (POX) de tecido foliar, aos 28 dias após o corte de uniformização, dos 14 genótipos de capim-elefante, selecionados para o semi-árido de Pernambuco. Designações dos genótipos: 1: Mole de Volta Grande; 2: Australiano; 3: HV-204; 4: HV-241; 5: HV-268; 6: HV-281; 7: HV-290; 8: HV-400; 9: HV-296; 10: Cameroon; 11: Gramafante; 12: Venezuela; 13: Elefante Roxo; 14: Elefante B. 
como os mais eficientes para análise de rotina, na identificação de acessos de aveia. Bassiri (1976), relatando a importância do sistema EST, comentou sobre a utilização de outros sistemas como complemento da EST na identificação de acessos de cevada.

\section{Diversidade genética}

Os números de bandas para os sistemas isoenzimáticos, utilizados para o cálculo do grau de similaridade genética, foram de 8, 3, 11 e 19 para ACP, GOT, POX e EST, respectivamente. Em que a presença de cada banda deve ser considerada de forma comparativa. Assim, por exemplo, duas amostras de indivíduos distintos que apresentarem três bandas de atividade, das quais apenas uma é comum a ambas, a similaridade genética entre elas é de $1 / 5$ ou 0,2 .

Os resultados relativos aos graus de similaridade genética das sete cultivares de capim-elefante mais seus sete híbridos com milheto, segundo o Índice de Jaccard, selecionadas para o semi-árido de Pernambuco, podem ser observados na Tabela 3, e representam frações de variantes eletroforéticas. Por exemplo, o híbrido HV-241 e a cultivar Cameroon apresentam 23 regiões de atividade, das quais 10 são comuns a ambas, o que resulta em uma similaridade

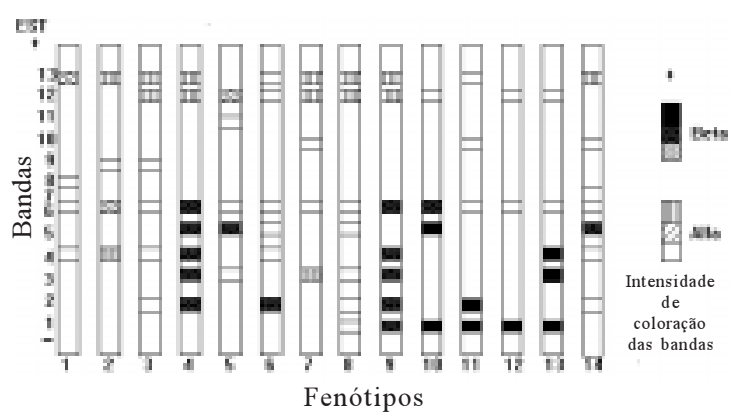

FIG. 4. Zimograma de esterase (EST) de tecido foliar, aos 28 dias após o corte de uniformização, dos 14 genótipos de capim-elefante, selecionados para o semi-árido de Pernambuco. Designações dos genótipos: 1: Mole de Volta Grande; 2: Australiano; 3: HV-204; 4: HV-241; 5: HV-268; 6: HV-281; 7: HV-290; 8: HV-400; 9: HV-296; 10: Cameroon; 11: Gramafante; 12: Venezuela; 13: Elefante Roxo; 14: Elefante B.

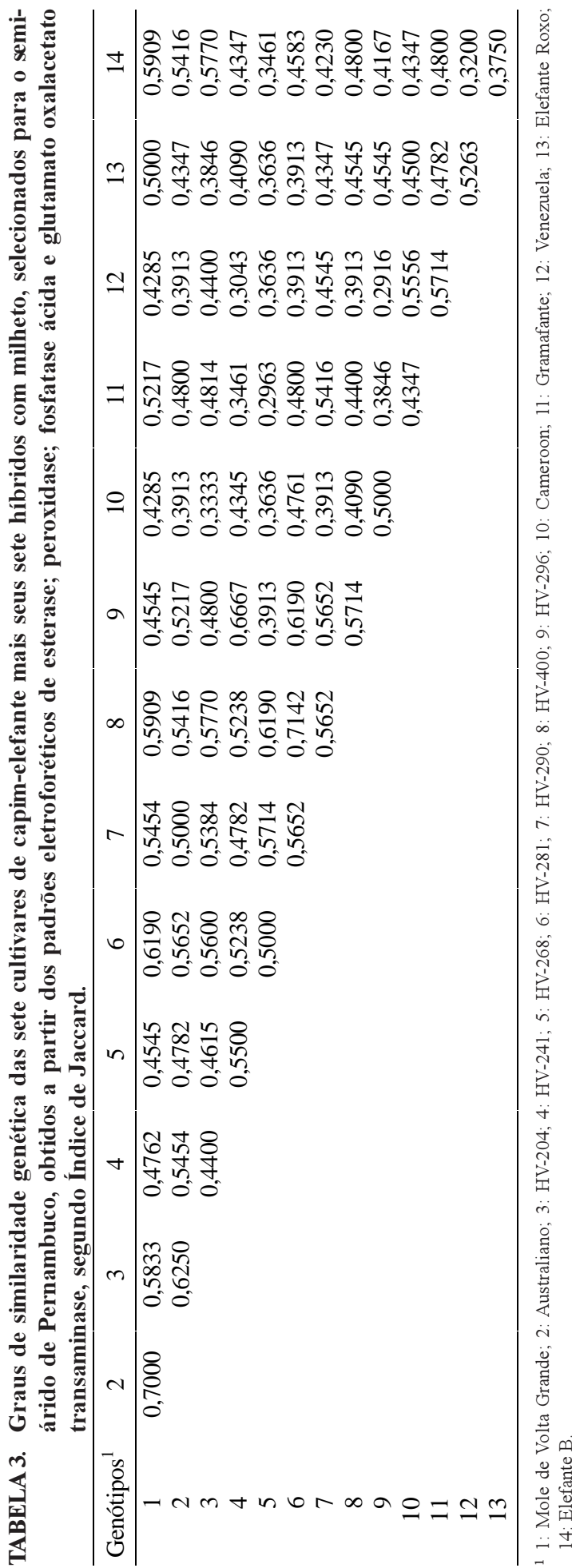

Pesq. agropec. bras., Brasília, v.35, n.6, p.1125-1133, jun. 2000 
genética de $10 / 23$ ou 0,4345 ou $43,45 \%$, isto é, a divisão do número de bandas comuns às duas amostras (espécies, populações, cultivares) pelo número total de bandas, considerando todos os sistemas que mostraram atividade, indica o quanto esses indivíduos são geneticamente próximos e, conseqüentemente, o quanto divergiram ao longo do caminho evolutivo.

Considerando as 91 comparações entre os 14 materiais, foi possível a distribuição dos coeficientes de similaridade em sete faixas, entre as quais foi determinado um intervalo de 0,0603 , do maior $(0,7142)$ ao menor $(0,2916)$ valor estimados. Como pode ser observado, para uma maioria de 63 comparações foi obtido grau de similaridade genética entre 0,4122 a 0,6534 , ou seja, nas três faixas intermediárias.

\section{CONCLUSÕES}

1. O sistema isoenzimático esterásico é o mais importante para a caracterização da coleção estudada.

2. Há uma considerável variabilidade genética nos padrões eletroforéticos, tanto das cultivares de capim-elefante como das cultivares híbridas de capimelefante vs. milheto.

3. Tecidos de folhas jovens coletados aos 28 dias após o corte de uniformização permitem a identificação dos acessos de forma rápida e segura.

4. Os sistemas isoenzimáticos da peroxidase, fosfatase ácida e glutamato oxalacetato transaminase, apesar de não individualizarem os materiais estudados, são úteis para a análise do grau de similaridade genética.

5. A análise do grau de similaridade genética evidencia uma considerável diversidade genética entre os acessos estudados.

\section{AGRADECIMENTOS}

À Fundação de Amparo à Pesquisa do Estado de Pernambuco (FACEPE) e ao Conselho Nacional de Desenvolvimento Científico e Tecnológico (CNPq), pelo auxílio financeiro prestado para o desenvolvimento deste trabalho.

\section{REFERÊNCIAS}

ALFENAS, A.C.; PETERS, I.; BRUNE, W.; PASSADOR, G.C. Eletroforese de proteínas e isoenzimas de fungos e essências vegetais. Viçosa : UFV, 1991. $243 p$

ALMGARD, G.; CLAPHAM, D. Isozyme variation distinguishing 18 Avena cultivars grown in Sweden Swedish of Journal of Agricultural Research, Oslo, n.5, p.61-67, 1975.

AUGUSTIN, E.; TCACENCO, F.A. Isoenzymatic characterization of elephant grass (Pennisetum purpureum Schum.) germoplasm. Revista Brasileira de Genética, Ribeirão Preto, v.16, p.685-696, 1993

BALLVE, R.M.L.; BORDIGNON, R.; MEDINA FILHO, H.P.; SIQUEIRA, W.J.; TEÓFILO SOBRINHO, J.; POMPEU JÚNIOR, J. Isoenzimas na identificação precoce de híbridos e clones nucelares no melhoramento de citros. Bragantia, Campinas, v.50, n.1, p.57-79, 1991

BALLVE, R.M.L.; MEDINA FILHO, H.P. BORDIGNON, R.; LIMA, M.M.A. Methodology for starch gel electrophoresis and protocols for isozymes of 32 plant genera. Brazilian Journal of Genetics, Ribeirão Preto, v.18, n.3, p.491-502, 1995.

BASSIRI, A. Barley cultivar identification by use of isozyme electrophoretic patterns. Canadian Journal of Plant Science, Ottawa, v.56, n.1, p.116,1976

DAHER, R.F. Diversidade morfológica e isoenzimática em capim-elefante (Pennisetum purpureum Schum.). Viçosa : UFV, 1993. 110p. Dissertação de Mestrado.

FALCÃO, T.M.M. de A.; FERNANDES, M.I.B. de M. Caracterização de cultivares de trigo (Triticum aestivum) através de padrões eletroforéticos esterásicos. Caderno Ômega, Série Biologia, Recife, n.4, p.117-124, 1994.

FALCÃO, T.M.M. de A.; PAULA, A. de P. Caracterização de cultivares de batata-doce (Ipomoea batatas (L.) Lam.) através da separação eletroforética de proteínas de raízes tuberosas. Caderno Ômega, Série Biologia, Recife, n.4, p.103-116, 1994

FERREIRA, M.E.; GRATTAPAGLIA, D. Introdução ao uso de marcadores RAPD e RFLP em análise genética. Brasília : Embrapa-Cenargen, 1995. 220p. 
FREITAS, N.S.A. de; BURITY, H.A.; FERNANDES, J.E.; SILVA, M.V. da. Caracterização de clones de acerola (Malpighia glabra L.) através dos sistemas isoenzimáticos peroxidase-esterase. Pesquisa Agropecuária Brasileira, Brasília, v.30, n.12, p.1453-1457, dez. 1995.

GONZALEZ, D.A.; MENEZES, M. O capim-elefante (elephant grass). Zootecnia, Nova Odessa, v.70, n.4, p.229-260, 1979.

GOTTLIEB, L.D. Eletrophoretic evidence and plant systematics. Missouri Botanical Garden Annals, St. Louis, v.64, p.161-180, 1977

GUPTA, V.P. Fodder improvement in Pennisetum. Forage Research, Madison, v.1, p.54-60, 1975

JONES, E.S.; LIU, C.J.; GALE, M.D.; HASH, C.T. Mapping quantitative trait loci for downy mildew resistance in pearl millet. Theoretical and Applied Genetics, Berlin, v.91, p.448-456, 1995.

KUMAR, A.; CHOWDHURY, R.K.; KAPOOR, R.L.; DAHIYA, O.S. Identification of pearl millet hybrids and their parental lines using seed and seedling characters, chemical tests and gel electrophoresis. Seed Science and Technology, Zurich, v.23, n.1, p.21-32, 1995

LARSEN, A.L. Isoenzymes and varietal identification Seed Word, Des Plaines, v.104, n. 8, p.5-6, 1969

MEDINA FILHO, H.P. Eletroforese em gel de amido: aplicações em genética e melhoramento de plantas. Campinas : Instituto Agronômico, 1983. 15p. (Circular, 121)

NAIR, P.S.; BRICIC, D.; KOJIMA, K.I. Isozyme variations and evolutionary relationships in the mesophoragmatica species group of Drosophila. Austin : University of Texas, 1971.28p. (University of Texas Publication, 7103).

OZIAS-AKINS, P.; FERL, R.J.; VASIL, I.K. Somatic hybridization in the gramineae: Pennisetum americanum (L.) K. Schum. (Pearl millet) + Panicum maximum Jacq. (Guinea grass). Molecular and General Genetics, Berlin, v.203, p.365-370, 1986.

PAULA, A. de P.O. Caracterização genético-bioquímica de sete cultivares de batata-doce (Ipomoea batatas (L.) Lam.) do banco de germoplasma da UFRPE. Recife : UFRPE, 1993. 149p. Dissertação de Mestrado.

PEREIRA, A.V. Germoplasma e diversidade genética do capim-elefante. In: SIMPÓSIO SOBRE CAPIMELEFANTE, 2., 1994, Coronel Pacheco. Anais. Coronel Pacheco : Embrapa-CNPGL, 1994. p.1-11.
PINTO, L.R.; SADER, R.; LEMOS, E.G. Variações nos perfis eletroforéticos de isoenzimas: aplicação na identificação de cultivares de soja. Revista Brasileira de Sementes, Brasília, v.17, n. 1, p.52-56, 1995.

POULIK, M.D. Starch gel eletrophoresis in a discontinuous system buffers. Nature, London, v.180, p.1477-1479, 1957.

QUIRÓS, C.F. Isoenzimas como marcadores genéticos para identificar híbridos en el cultivo de tejidos. In: ROCA, W.M.; MROGÍNSKI, L.A. (Ed.). Cultivo de tejidos en la agricultura: fundamentos y aplicaciones. Cali : CIAT, 1991. cap.37, p.857-876.

SANTANA, J.R.; PEREIRA, J.M.; ARRUDA, N.G.; RUIZ, M.A.M. Avaliação de cultivares de capimelefante (Pennisetum purpureum Schum) no Sul do Bahia. I. Agrossistema cacaueiro. Revista da Sociedade Brasileira de Zootecnia, Viçosa, v.18, n.3, p.273-283, 1989.

SASTRV, J.G.; RAMAKRISHNA, W. SIVARAMAKRIHNAN, S.; THAKUR, R.P. DNA fingerprinting detects genetic variability in the pearl millet downy mildew pathogen (Sclerospora graminicola). Theoretical and Applied Genetics, Berlin, v.91, p.856-861, 1995.

SCANDALIOS, J.G. Genetic control of multiple molecular forms of enzymes in plants: a review. Biochemical Genetics, New York, v.3, p.37-39, 1969.

SCHANK, S.C. Vegetative and sexual propagation of elephant grass. In: SIMPÓSIO SOBRE CAPIMELEFANTE, 2., 1994, Coronel Pacheco. Anais Coronel Pacheco : Embrapa-CNPGL, 1994. p.57-71.

SHAW, C.R.; PRASAD, R. Starch gel electrophoresis of enzymes: a compilation of recipes. Biochemical Genetics, New York, v.4, p.297-299, 1970

TABAEIZADEH, Z.; FERL, R.J.; VASIL, I.K. Somatic hybridization in Gramineae: Saccharum officinarum L. (sugarcane) and Pennisetum americanum (L.) K. Schum. (pearl millet). National Academy of Sciences of the United States of America. Proceedings, Washington, v.83, p.5616-5619, 1986.

TANKSLEY, S.D.; ORTON, T.J. Isozymes in plant genetics and breeding. Amsterdam : Elsevier Science, 1983. part A. 516p.

TCACENCO, F.A.; BOTREL, M.A. Identificação e avaliação de acessos e cultivares de capim-elefante. In: SIMPÓSIO SOBRE CAPIM-ELEFANTE, 2., 1990, Coronel Pacheco. Anais. Coronel Pacheco : EmbrapaCNPGL, 1990. p.1-22.

Pesq. agropec. bras., Brasília, v.35, n.6, p.1125-1133, jun. 2000 